\title{
LINEAR TRANSFORMATIONS ON OR ONTO A BANACH SPACE
}

\author{
H. D. BLOCK
}

We investigate here a simple property of linear transformations which are not necessarily bounded or closed or one-to-one, but whose domain or range is all of a Banach space.

THEOREM 1. Let $T$ be a linear transformation from (all of) a Banach space $\mathfrak{X}$ onto a normed vector space $Y$. Then there is a number $m>0$ such that for any $x \in \mathfrak{X}$ there exists a sequence $x_{n} \rightarrow x$ such that $\left\|T x_{n}\right\|$ $\leqq m\|x\|$ and $\left\{T x_{n}\right\}$ converges in the sense of Cauchy.

Proof. Let $C_{n}$ be the set of all $x \in \mathfrak{X}$ such that $\|T x\| \leqq n$ $(n=1,2,3, \cdots)$. Then $\mathfrak{X}=\sum_{n=1}^{\infty} C_{n}$. In virtue of the Baire category principle there is an integer $k$ such that $\bar{C}_{k}$ contains a closed sphere, $S$, whose center and radius we denote by $x_{0}$ and $r$, respectively. Let $\left\|T x_{0}\right\|=b$. Thus for each $z$ such that $\left\|z-x_{0}\right\| \leqq r$ there exists a sequence $z_{n} \rightarrow z$ with $\left\|T z_{n}\right\| \leqq k$. Take $m=2(k+b) / r$.

Now let $x \in \mathfrak{X}$ be given. It suffices to consider $x \neq 0$, for if $x=0$, the theorem is obvious if we use the sequence $x_{n}=0$. Let $z=x_{0}$ $+r x /\|x\|$. Then $z_{n} \rightarrow z$ with $\left\|T z_{n}\right\| \leqq k$. Let $x_{n}^{\prime}=(\|x\| / r)\left(z_{n}-x_{0}\right)$. Then $x_{n}^{\prime} \rightarrow x$ and $\left\|T x_{n}^{\prime}\right\| \leqq((k+b) / r)\|x\|=(m / 2)\|x\|$. Now we shall construct a sequence $\left\{x_{n}\right\}$ such that $\left\{T x_{n}\right\}$ is, in addition, Cauchy convergent. For this we use the following lemma.

Lemma. For a given $x \in \mathfrak{X}, x^{\prime} \in \mathfrak{X}$, there exists a sequence $u_{n} \rightarrow x$ with $\left\|T x^{\prime}-T u_{n}\right\| \leqq(m / 2)\left\|x-x^{\prime}\right\|$.

Proof. Applying the result already proved to the element $x-x^{\prime}$ we have $x_{n}^{\prime \prime} \rightarrow x-x^{\prime}$ with $\left\|T x_{n}^{\prime \prime}\right\| \leqq(m / 2)\left\|x-x^{\prime}\right\|$. Let $u_{n}=x^{\prime}+x_{n}^{\prime \prime}$. Then $u_{n} \rightarrow x$ and $\left\|T u_{n}-T x^{\prime}\right\|=\left\|T x_{n}^{\prime \prime}\right\| \leqq(m / 2)\left\|x-x^{\prime}\right\|$, as asserted.

To complete the proof of the theorem take $n_{1}$ large enough so that $\left\|x-x_{n_{1}}^{\prime}\right\| \leqq\|x\| / 2$ and $\left\|T x_{n_{1}}^{\prime}\right\| \leqq(m / 2)\|x\|$. Let $x_{1}=x_{n_{1}}^{\prime}$. By the lemma, $u_{n}^{(1)} \rightarrow x$ with $\left\|T x_{1}-T u_{n}^{(1)}\right\| \leqq(m / 4)\|x\|$. Let $n_{2}$ be large enough so that $\left\|u_{n_{2}}^{(1)}-x\right\| \leqq\|x\| / 2^{2}$ and take $x_{2}=u_{n_{2}}^{(1)}$. Again by the lemma, there exists $u_{n}^{(2)} \rightarrow x$ with $\left\|T x_{2}-T u_{n}^{(2)}\right\| \leqq m\|x\| / 2^{3}$. Take $n_{3}$ large enough so that $\left\|u_{n_{3}}^{(2)}-x\right\| \leqq\left(m / 2^{3}\right)\|x\|$ and let $x_{3}=u_{n_{3}}^{(2)}$. Continuing in this manner we have

$$
\left\|T x_{1}\right\| \leqq \frac{m}{2}\|x\|
$$

Received by the editors May 10, 1951. 


$$
\begin{aligned}
& \left\|T x_{1}-T x_{2}\right\| \leqq \frac{m}{4}\|x\|, \\
& \left\|T x_{3}-T x_{2}\right\| \leqq \frac{m}{2^{3}}\|x\|, \\
& \cdot . \cdot . \cdot . \cdot \cdot \cdot \cdot, \\
& \left\|T x_{n}-T x_{n-1}\right\| \leqq \frac{m}{2^{n}}\|x\|, \text { and }\left\|x-x_{n}\right\| \leqq \frac{m}{2^{n}} .
\end{aligned}
$$

Thus $x_{n} \rightarrow x$ and for $p>q \geqq 1$ : $\left\|T x_{p}-T x_{q}\right\|=\| T x_{p}-T x_{p-1}+T x_{p-1}$ $\cdots+T x_{q+1}-T x_{q}\|\leqq m\| x\left\|\left(1 / 2^{q+1}+\cdots+1 / 2^{p}\right) \leqq m\right\| x \| / 2^{q}$, which proves that the $\left\{T x_{n}\right\}$ converges in the sense of Cauchy. Finally

$$
\begin{aligned}
\left\|T x_{n}\right\| & =\left\|T x_{n}-T x_{n-1}+T x_{n-1}-\cdots-T x_{1}+T x_{1}\right\| \\
& \leqq\left\|T x_{n}-T x_{n-1}\right\|+\cdots+\left\|T x_{2}-T x_{1}\right\|+\left\|T x_{1}\right\| \\
& \leqq m\|x\|\left(\frac{1}{2^{n}}+\cdots+\frac{1}{2^{2}}\right)+\frac{m}{2}\|x\| \leqq m\|x\| .
\end{aligned}
$$

It might be remarked that the closed graph theorem is an immediate corollary of this theorem (that is, if $T$ is everywhere defined on a Banach space, then it is closed if and only if it is bounded). A further corollary is the fact that if $T$ is everywhere defined and not closed, then for each $x \in \mathfrak{X}$ there exist three sequences $x_{n}^{(1)} \rightarrow x$, $x_{n}^{(2)} \rightarrow x, x_{n}^{(3)} \rightarrow x$ with $T x_{n}^{(1)} \rightarrow \infty, T x_{n}^{(2)} \rightarrow T x, T x_{n}^{(3)} \rightarrow y$ with $\|y\| \leqq m\|x\|$, where $m$ is independent of $x$.

THEOREM 2. Let $T$ be a linear transformation from a normed vector space $X$ onto (all of) a Banach space $Y$. Then there exists a number $m>0$ such that for any $y \in Y$, there exists a sequence $y_{n} \rightarrow y$ with $y_{n}$ $=T x_{n},\left\|x_{n}\right\| \leqq m\|y\|$, and $\left\{x_{n}\right\}$ convergent in the sense of Cauchy.

Proof. The method is entirely analogous to that of Theorem 1 but we give the details. Let $C_{n}$ be the set of all $y \in Y$ such that $y=T x$ with $\|x\| \leqq n(n=1,2,3, \cdots)$. Then $Y=\sum_{n=1}^{\infty} C_{n}$. Hence there exists an integer $k$ such that $\bar{C}_{k}$ contains a sphere whose center and radius we denote by $y_{0}$ and $r$ respectively. Say $y_{0}=T x_{0}$, with $\left\|x_{0}\right\|$ $=b$. Let $m=2(b+k) / r$. For any $z \in Y$ such that $\left\|z-y_{0}\right\| \leqq r$ there exists $z_{n} \rightarrow z$ with $z_{n}=T \xi_{n}$ and $\left\|\xi_{n}\right\| \leqq k$. Let $y \in Y$ be given. Clearly it suffices to consider $y \neq 0$. Let $z=y_{0}+(r /\|y\|) y$. Then the $z_{n}$ described above exists. Let $y_{n}^{\prime}=(\|y\| / r)\left(z_{n}-y_{0}\right)$. Then $y_{n}^{\prime} \rightarrow y, y_{n}^{\prime}=T x_{n}^{\prime}$ (where $\left.x_{n}^{\prime}=(\|y\| / r)\left(\xi_{n}-x_{0}\right)\right)$, and $\left\|x_{n}^{\prime}\right\| \leqq((k+b) / r)\|y\|=(m / 2)\|y\|$.

Now we shall construct a sequence $\left\{y_{n}\right\}$ such that $\left\{y_{n}\right\}$ is, in 
addition, Cauchy convergent. Again we use a lemma.

LEMmA. For a given $y \in Y, y^{\prime}=T x^{\prime} \in Y$ there exists a sequence $v_{n} \rightarrow y$ with $v_{n}=T u_{n}$ and $\left\|u_{n}-x^{\prime}\right\| \leqq(m / 2)\left\|y-y^{\prime}\right\|$.

Proof. Applying the result already established to the element $y-y^{\prime}$, we have $y_{n}^{\prime \prime} \rightarrow y-y^{\prime}, y_{n}^{\prime \prime}=T x_{n}^{\prime \prime},\left\|x_{n}^{\prime \prime}\right\| \leqq(m / 2)\left\|y-y^{\prime}\right\|$. Set $v_{n}=y^{\prime}$ $+y_{n}^{\prime \prime}$. Then $v_{n} \rightarrow y, v_{n}=T u_{n}$ (with $u_{n}=x^{\prime}+x_{n}^{\prime \prime}$ ), and $\left\|u_{n}-x^{\prime}\right\|=\left\|x_{n}^{\prime \prime}\right\|$ $\leqq(m / 2)\left\|y-y^{\prime}\right\|$, as asserted. To complete the proof of the theorem select $n_{1}$ large enough so that $\left\|y_{n_{1}}^{\prime}-y\right\| \leqq\|y\| / 2$. Let $y_{n_{1}}^{\prime}=y_{1}, x_{n_{1}}^{\prime}=x_{1}$. Then $y_{1}=T x_{1},\left\|x_{1}\right\| \leqq(m / 2)\|y\|$. Take $n_{2}$ large enough (by the lemma) so that $\left\|v_{n_{2}}-y\right\| \leqq\|y\| / 4, \quad v_{n_{2}}=T u_{n_{2}}$, and $\left\|u_{n_{2}}-x_{1}\right\| \leqq(m / 2)\left\|y-y_{1}\right\|$ $\leqq(m / 4)\|y\|$. Let $v_{n_{2}}=y_{2}, u_{n_{2}}=x_{2}$. Take $n_{3}$ large enough so that $\left\|v_{n_{3}}-y\right\| \leqq\|y\| / 2^{3}, \quad v_{n_{3}}=T u_{n_{3}}, \quad\left\|u_{n_{3}}-x_{2}\right\| \leqq(m / 2)\left\|y-y_{2}\right\| \leqq\left(m / 2^{3}\right)\|y\|$. Let $v_{n_{3}}=y_{3}, u_{n_{3}}=x_{3}$. Continuing in this manner we find a sequence $y_{n}=T x_{n},\left\|y_{n}-y\right\| \leqq\|y\| / 2^{n},\left\|x_{n}-x_{n-1}\right\| \leqq\left(m / 2^{n}\right)\|y\|$. Thus $y_{n} \rightarrow y$. For $p>q \geqq 1$,

$$
\begin{aligned}
\left\|x_{p}-x_{q}\right\| & =\left\|x_{p}-x_{p-1}+x_{p-1}-\cdots+x_{q+1}-x_{q}\right\| \\
& \leqq m\|y\|\left(\frac{1}{2^{p}}+\cdots+\frac{1}{2^{q+1}}\right) \leqq \frac{m\|y\|}{2^{q}}
\end{aligned}
$$

so that $\left\{x_{n}\right\}$ converges in the sense of Cauchy. Finally

$$
\begin{aligned}
\left\|x_{n}\right\| & =\left\|x_{n}-x_{n-1}+x_{n-1}-\cdots+x_{2}-x_{1}+x_{1}\right\| \\
& \leqq m\|y\|\left(\frac{1}{2^{n}}+\cdots+\frac{1}{2^{2}}+\frac{1}{2}\right) \leqq m\|y\| .
\end{aligned}
$$

Iowa State College 